Original Research Article

\title{
Assessment of quality of life measured by rhinoconjuctivits quality of life questionnaire in patients of allergic rhinitis treated with commonly used oral antihistaminics
}

\author{
Ganesh S. Pentewar*, Ranjit J. Wagh
}

Department of Pharmacology, MIMER Medical College,

Talegaon Dabhade,

Maharashtra, India

Received: 24 May 2019

Accepted: 06 July 2019

*Correspondence to:

Dr. Ganesh S Pentewar,

Email: drpentewarganesh@

gmail.com

Copyright: (C) the author(s), publisher and licensee Medip Academy. This is an openaccess article distributed under the terms of the Creative Commons Attribution NonCommercial License, which permits unrestricted noncommercial use, distribution, and reproduction in any medium, provided the original work is properly cited.

\begin{abstract}
Background: Nasal and non-nasal symptoms in allergic rhinitis (AR) can be assessed by measuring health related quality of life (HRQOL). Present study was to assess the impact of use of antihistaminic in AR which will affect the work productivity, sleep, frequent visits to health care professional and expenditure on medicines. For this evaluation, Rhinoconjuctivits Quality Of Life Questionnaire (RQLQ) has been used.

Methods: In this study 52 patients with AR were randomized in an open-label, 4-arm, parallel group, single center study. Questionnaire information was obtained about allergy-related RQLQ. Subjects received either Tablet Cetirizine $5 \mathrm{mg}$, Levocetirizine $5 \mathrm{mg}$, Loratidine $5 \mathrm{mg}$ or Fexofenadine $120 \mathrm{mg}$. Changes from baseline until the end of study visit (1 week following) were evaluated by RQLQ.

Results: When compared between treatment groups using one-way ANOVA it was observed that there is no variation in RQLQ overall Score in all the four treatment groups and there is no difference from treatment to treatment. Overall RQLQ score was reduced maximum in Levocetirizine group. Individual symptoms of RQLQ that is sleep score, non-hay fever, practical problem, nasal symptom score, Eye symptom Score, activities Score, and emotion score were also improved in the Levocetirizine group.

Conclusions: Patients of all four study groups showed an improved perception of their HRQL according to the RQLQ. Significant improvements are reported in nasal symptoms, daily activities, sleep and psychological impact. Our results provide support for an AR and its impact on quality of life. Our recommendation stipulating that levocetirizine is superior to rest drug group for the treatment of AR with safety and tolerability.
\end{abstract}

Keywords: Allergic rhinitis, Antihistaminic, Quality of life, RQLQ

\section{INTRODUCTION}

At any age, allergic rhinitis can compromise Quality of life (QOL) and often manifested by sleep disorders, impairment at work, limitations of activities, or impairment of social functioning. As evidence of the disparities between patients' and physicians' perspectives of allergic rhinitis, the symptom severity and the reduced work and social functioning as indicators of QOL are often under recognized and inadequately treated by the physician. Understanding the impact of allergic rhinitis on the patient's QOL represent the cornerstone of therapy. ${ }^{1}$ The effect of rhinitis on QOL has been measured using both generic and disease specific questionnaires. The advantage of using a generic questionnaire is that the burden of rhinitis can be compared with other diseases, such as asthma. In fact, in adults, moderate to severe perennial rhinitis and moderate to severe asthma have equal functional impairment. ${ }^{2,3}$ 
On the other hand, disease specific QOL questionnaires describe disease associated problems more accurately and seem to be more responsive to measuring the change with therapeutic interventions. Adult generic questionnaires include the Sickness Impact Profile, the Duke Health Profile, the Nottingham Health Profile, and the Medical Outcome Survey Short Form 36. ${ }^{1}$ The Short Form 36 has been used to evaluate the effects of a non-sedating H1antihistamine on QOL. ${ }^{4}$ (SF-36) is a well validated questionnaire to measure health status. The SF-36 is a generic measure that is, it does not target a specific age, disease, or treatment group. As such, the SF-36 has been widely used to assess the relative burden of various diseases, including allergic rhinitis. ${ }^{2}$

Generic QOL questionnaires in children, such as the Child Health Questionnaire Parental Form 50, Paediatric Quality of Life Inventory, and SF-10, are used at times for comparing different allergic diseases. Disease-specific rhinitis QOL questionnaires have been adapted to different age groups.

For example, when studying rhinitis in children the Juniper Paediatric Rhino conjunctivitis Quality of Life Questionnaire (RQLQ), can be used for ages 6 to 12 years and Juniper Adolescent RQLQ for ages 12 to 20 years. ${ }^{5-9}$ The use of a modified visual analogue scale (VAS) for assessing the severity of allergic rhinitis has been recommended for the clinician when assessing the individual patient for nasal and non-nasal symptom severity, and QOL assessment of rhinitis severity. ${ }^{10}$

In this study patient of allergic rhinitis included are in between age group 18 years to 55 years so that we have selected Adolescent RQLQ.

\section{METHODS}

\section{Study type/ Design and Study location}

The present study is single centered, open label, Randomized, Four Arm, parallel-group, comparative clinical study between orally administered Cetirizine, Levocetirizine, Loratadine and Fexofenadine in patients with Allergic Rhinitis (AR) conducted at a tertiary care hospital in rural Maval Taluka in Pune district of Maharashtra State.

\section{Enrollment}

Potential patients were identified from the ear nose and throat outpatient department. Once identified, they were briefed about the study and activities. If they were apparently willing to take part in the study, a copy of a patient information sheet and informed consent form was given to patient.

The study was approved by Institutional Ethical Committee and procedures followed in this study were accordance with the ethical standard laid down by Indian
Council of Medical Research (ICMR)'s ethical guidelines for biomedical research on human subjects (2006).

They were given adequate time to decide to take part in the study, and if willing, a written informed consent was taken from all the patients participated in the study after explaining the patient's diagnosis, the nature and purpose of a proposed treatment, the risks and benefits of a proposed treatment and the risks and benefits of the alternative treatment. Study related activity was started only after obtaining the informed consent form. The process was documented in the source notes. A copy of the patient diary was issued to patient and asked them to record as per instruction.

\section{Inclusion criteria}

- Patient with a clinical history of AR.

- Patients aged above 18 years inclusive of either sex.

- The combined score of Total nasal symptoms score (TNSS) (nasal congestion, rhinorrhea, nasal itching, sneezing) must be at least 8 and nasal congestion severity score (NCSS) must be at least 3 at screening.

- Patient with ability to understand and sign written informed consent form, which must have been obtained prior to screening.

- Patients willing to comply with the protocol requirements.

\section{Exclusion criteria}

- Known hypersensitivity to antihistaminic.

- Concomitant medications that could affect the efficacy of study drugs.

- Clinically significant nasal disease (other than AR) or significant nasal structural abnormalities including nasal polyps.

- Asthma requiring chronic use of inhaled or systemic corticosteroids.

- Pregnant or lactating women.

\section{Randomization}

At the Baseline visit, after confirming the study subjects who fulfilled the eligibility criteria and returned the duly signed Informed consent forms, a total of 52 patients (13 per each group) were assigned sequentially to each of the 4 study groups.

All the study patients received their respective medication orally daily in the evening for 1 week period.

- Cetirizine Group: Tab Cetirizine Hydrochloride $10 \mathrm{mg}$

- Levocetirizine Group: Tab Levocetirizine Hydrochloride $5 \mathrm{mg}$

- Loratadine Group: Tab Loratadine $10 \mathrm{mg}$

- Fexofenadine Group: Tab Fexofenadine Hydrochloride $120 \mathrm{mg}$ 
Visit 1: Baseline Screening and Randomization to study treatment group (Day 1)

Following procedures were performed on the first day of the subject enrolment,

- Medical history

- Physical Examination and Vital signs

- Filling of Rhino conjunctivitis Quality of Life questionnaire (RQLQ) by using 7 point scale before study drug treatment

- Issue of study medications for 1 week treatment

Visit 2: End of study (Day 8)

Following procedures were performed on the eighth day,

- Physical Examination and Vital signs

- Patient Compliance (Recording in Patient Diary)

- Filling of Rhino conjunctivitis Quality of Life questionnaire (RQLQ) by using 7 point scale after study drug treatment

- Return of Patient Diary

\section{Efficacy assessment}

Patients were provided with Patient's Diary. This was filled by Patient in the morning at the time of Screening and Randomization visit and in the evening (immediately before study drug administration) to obtain the baseline and study score of Nasal and Non-nasal symptoms score.

Mean change in Rhino conjunctivitis Quality of Life Questionnaire Score from Baseline to End of the treatment

Following are 28 questions in 7 domains on Rhino conjunctivitis Quality of Life Questionnaire were asked to Patient at visit 1 to obtain the Baseline value and at visit 2 to obtain the at the end of treatment.

- $\quad$ Sleep: Difficulty Getting to Sleep, Wake Up During the Night, Lack of a Good Night's Sleep.

- Non-Hay Fever Symptoms: Fatigue, Tiredness, Thirst, Poor concentration, Reduced productivity, Headache, Worn out.

- Practical Problems: Inconvenience of having to carry tissues or handkerchief, need to rub nose/eyes, need to blow your nose repeatedly.

- Nasal Symptoms: Stuffy or Blocked Nose, Runny Nose, Sneezing.

- $\quad$ Eye Symptoms: Itchy Eyes, Watery Eyes, Sore Eyes, Swollen Eyes.

- Activities: The patient was asked to identify three activities that have been limited by the nose or eyes symptoms during the previous week. The patient was then asked how troubled have been by each of these activities during the last week as a result of your nose or eye symptoms? Regular activities at Home and at work, Social activities, Outdoors activities.
- Emotional: How often during the last week have you been troubled by these emotions as a result of your nose or eye symptoms? Frustrated, Impatient or Restless, Irritable, Embarrassed by Your Symptoms.

\section{Scoring Pattern}

Each of the quality of life domains (Nos. 1-6) i.e. Sleep, Non-Hay Fever Symptoms, Practical Problems, Nasal Symptoms, Eye Symptoms and Activities will be rated by the Patient on a 7-point scale as follows:

\section{Score description}

In which 6 Extremely troubled, 5 Very troubled, 4 Quite a bit troubled, 3 Moderately troubled, 2 Somewhat troubled,1 Hardly troubled, 0 Not troubled. The quality of life domain No. 7 i.e. Emotional was rated by the Patient on a 7-point scale as follows: And 6 All the time, 5 Most of the time, 4 A good part of the time, 3 Some of the time, 2 A small part of time, 1 Hardly any time at all, 0 None of the time.

\section{Statistical analysis}

Statistical analysis was performed using the statistical software Microsoft SPSS 19.0. (SPSS Inc., Chicago, USA). Data was summarized using Mean, Median and Standard Deviation.

'Paired t' test was used to compare Mean changes in patients before and after treatment. Probability $<0.05$ was considered statistically significant. Analysis of variance was used to compare treatment groups for the quantitative primary and secondary outcomes. In case of significant results, subsequent pairwise contrasts using a Bonferroni adjustment were made between the treatment groups. The statistician was blinded to the groups during analysis.

\section{RESULTS}

A total of 52 patients 13 in each groups of the age group 18 to 65 years (Mean age, $33.73 \pm 10.23$ years); $48.08 \%$ are Female and $51.92 \%$ are Male were randomized and received either Cetirizine, Levocetirizine, Loratadine or Fexofenadine over a period of one week. Mean compliance with treatment was $100 \%$ for all four treatment groups. The baseline demographic data and clinical characteristics of all 52 patients participated in this study have been compared in the Table 1.

Using one-way ANOVA, it was observed that there is no variation in RQLQ overall Score in all the four treatment groups and there is no difference from treatment to treatment When compared between treatment groups in the Table 2. ANOVA comparison between groups $(<0.05)$ i.e. Sleep Score differs significantly for all the treatment groups. Subsequent pairwise contrasts using a Bonferroni adjustment reveals maximum reduction in Levocetirizine. Sleep Score differs significantly for all the treatment groups in the Table 3. 
When compared between treatment groups using one-way ANOVA it was observed that there is no variation in Non-Hay Fever Score in all the four treatment groups and there is no difference from treatment to treatment in the Table 4.
When compared between treatment groups using one-way ANOVA it was observed that there is no variation in Practical Problem score in all the four treatment groups and there is no difference from treatment to treatment in the Table 5.

Table 1: Comparison of demographic data and clinical characteristics of the patients participated in the study $(n=52)$.

\begin{tabular}{|llllllll|}
\hline Parameters & Cetirizine $(\mathbf{n}=\mathbf{1 3})$ & $\begin{array}{l}\text { Levocetirizine } \\
(\mathbf{n}=\mathbf{1 3})\end{array}$ & $\begin{array}{l}\text { Loratadine } \\
(\mathbf{n}=\mathbf{1 3})\end{array}$ & $\begin{array}{l}\text { Fexofenadine } \\
(\mathbf{n}=\mathbf{1 3})\end{array}$ & $\mathbf{F}^{*}$ & $\mathbf{p}^{*}$ \\
\hline Age (years) & $31.85 \pm 9.45$ & $39.38 \pm 14.39$ & $32 \pm 1.011$ & $31.69 \pm 7.22$ & 1.858 & 0.149 \\
\hline \multirow{2}{*}{ Sex } & Male (\%) & $6(46.16 \%)$ & $4(30.77 \%)$ & $7(53.84 \%)$ & $10(76.92 \%)$ & & \\
\cline { 2 - 8 } & Female (\%) & $7(53.84 \%)$ & $9(69.23 \%)$ & $6(46.16 \%)$ & $3(23.08 \%)$ & & \\
\hline TNSS & $12 \pm 1.22$ & $10.69 \pm 1.25$ & $10.76 \pm 1.48$ & $10.92 \pm 1.44$ & 0.461 & 0.635 \\
\hline NCS & $4.46 \pm 0.66$ & $3.87 \pm 0.68$ & $4 \pm 0.82$ & $4.15 \pm 0.55$ & 1.905 & 0.141 \\
\hline
\end{tabular}

The values are expressed as mean \pm SD, Total Nasal Symptom Score (TNSS), NCS = Nasal congestion score, *one way ANOVA.

Table 2: Comparison of Rhino conjunctivitis Quality of Life Questionnaire (RQLQ) Overall Score before and after treatment.

\begin{tabular}{|c|c|c|c|c|c|}
\hline \multirow{2}{*}{ Groups $(\mathbf{n}=\mathbf{1 3})$} & \multicolumn{5}{|c|}{ RQLQ Overall score } \\
\hline & Baseline score & End of treatment score & Mean change in score & $\mathbf{t}$ & $\mathbf{p}$ \\
\hline Cetirizine & $1.81 \pm 0.59$ & $0.91 \pm 0.71$ & $0.9 \pm-0.12$ & 5.03 & $<0.0001^{* * *}$ \\
\hline Levocetrizine & $1.95 \pm 0.57$ & $0.67 \pm 0.55$ & $1.28 \pm 0.02$ & 6.82 & $<0.0001^{* * *}$ \\
\hline Loratadine & $1.69 \pm 0.57$ & $0.63 \pm 1.06$ & $1.06 \pm-0.49$ & 4.322 & $<0.0001^{* * *}$ \\
\hline Fexofenadine & $1.58 \pm 0.53$ & $0.59 \pm .38$ & $0.99 \pm 0.15$ & 7.530 & $<0.0001^{* * *}$ \\
\hline $\mathrm{F}$ & 1.001 & 0.531 & & & \\
\hline $\mathrm{p}$ & 0.401 & 0.663 & & & \\
\hline
\end{tabular}

RQLQ Overall score=Mean of Sleep Problems, Non-Hay Fever, Practical Problems, Nasal symptoms, Eye symptoms, Activity limitation, and Emotional function, the values are expressed as mean $\pm \mathrm{SD}, \mathrm{n}=13$ patient. ***represents statistically significant of $\mathrm{p}<0.0001$ when compared before and after treatment (Paired ' $\mathrm{t}$ ' test).

Table 3: Comparison of Sleep Score before and after treatment.

\begin{tabular}{|llllll|}
\hline Groups $(\mathbf{n = 1 3})$ & $\begin{array}{l}\text { Sleep score } \\
\text { Baseline score }\end{array}$ & End of treatment score & Mean change in score & t & p \\
\hline Cetirizine & $1.69 \pm 0.85$ & $0.967 \pm 0.44$ & $0.723 \pm 0.59$ & 4.38 & $<0.001^{* *}$ \\
\hline Levocetrizine & $1.54 \pm 0.77$ & $0.56 \pm 0.23$ & $0.98 \pm-0.58$ & 5.31 & $<0.001^{* *}$ \\
\hline Loratadine & $1.61 \pm 0.76$ & $0.59 \pm 0.39$ & $1.02 \pm 0.36$ & 8.61 & $<0.001^{* *}$ \\
\hline Fexofenadine & $1.54 \pm 0.77$ & $0.76 \pm 0.32$ & $0.78 \pm 0.45$ & 5.31 & $<0.001^{* *}$ \\
\hline F & 0.112 & 3.489 & & & \\
\hline p & 0.953 & 0.023 & & & \\
\hline
\end{tabular}

The values are expressed as mean $\pm \mathrm{SD}, \mathrm{n}=13$ patient. **represents statistically significant of $\mathrm{p}<0.001$ when compared before and after treatment (Paired ' $\mathrm{t}$ ' test), significant at $\mathrm{p}<0.05$ when compared between treatment groups using one-way ANOVA with post-hoc Bonferroni's test.

Table 4: Comparison of Non-Hay fever score for each treatment before and after treatment.

\begin{tabular}{|c|c|c|c|c|c|}
\hline \multirow{2}{*}{ Groups(n=13) } & \multicolumn{5}{|c|}{ Non-Hay Fever Score } \\
\hline & Baseline score & End of treatment score & Mean change in score & $\mathbf{t}$ & $\mathbf{p}$ \\
\hline Cetirizine & $0.462 \pm 0.52$ & $0.076 \pm 0.28$ & $0.38 \pm 0.24$ & 2.74 & $0.018^{*}$ \\
\hline Levocetrizine & $0.462 \pm 0.518$ & $0 \pm 0$ & $0.462 \pm 0.56$ & 3.207 & $0.008^{*}$ \\
\hline Loratadine & $0.308 \pm 0.48$ & $0.077 \pm 0.28$ & $0.23 \pm 0.20$ & 1.389 & 0.190 \\
\hline Fexofenadine & $0.769 \pm 0.438$ & $0 \pm 0$ & $0.769 \pm 0.44$ & 6.325 & $<0.0001 * * *$ \\
\hline $\mathrm{F}$ & 2.027 & 0.667 & & & \\
\hline $\mathrm{p}$ & 0.123 & 0.577 & & & \\
\hline
\end{tabular}

The values are expressed as mean $\pm \mathrm{SD}, \mathrm{n}=13$ patient. *represents statistically significant of $\mathrm{p}<0.05$ when compared before and after treatment (Paired ' $\mathrm{t}$ ' test), ${ }^{* * *}$ significant at $\mathrm{p}<0.0001$ when compared before and after treatment (Paired ' $\mathrm{t}$ ' test). 
When compared between treatment groups using one-way ANOVA it was observed that there is no variation in Nasal Symptom score in all the four treatment groups before or after treatment i.e. significant reduction in Nasal Symptom was observed in all the four groups and there is no difference from treatment to treatment before or after the treatment in the Table 6 . When compared between treatment groups using one-way ANOVA it was observed that there is no variation in Eye symptoms Score in all the four treatment groups and there is no difference from treatment to treatment in the Table 7.

Table 5: Comparison of practical problems score for each treatment before and after treatment.

\begin{tabular}{|c|c|c|c|c|c|}
\hline \multirow{2}{*}{ Groups(n=13) } & \multicolumn{5}{|c|}{ Practical problems score } \\
\hline & Baseline score & End of treatment score & Mean change in score & $\mathbf{t}$ & $\mathbf{p}$ \\
\hline Cetirizine & $3.77 \pm 0.93$ & $2.15 \pm 1.6$ & $1.62 \pm-0.65$ & 4.395 & $0.0001 * *$ \\
\hline Levocetrizine & $4.62 \pm 1.61$ & $1.23 \pm 1.87$ & $3.38 \pm-0.27$ & 6.590 & $0.0001 * *$ \\
\hline Loratadine & $3.60 \pm 0.96$ & $1.61 \pm 1.26$ & $2 \pm-0.30$ & 5.586 & $0.0001 * *$ \\
\hline Fexofenadine & $3.85 \pm 1.2$ & $1.61 \pm 1.6$ & $2.23 \pm-0.39$ & 6.618 & $0.0001 * *$ \\
\hline $\mathrm{F}$ & 1.772 & 0.736 & & & \\
\hline $\mathrm{p}$ & 0.165 & 0.536 & & & \\
\hline
\end{tabular}

The values are expressed as mean $\pm \mathrm{SD}, \mathrm{n}=13$ patient. $* * *$ represents statistically significant of $\mathrm{p}<0.0001$ when compared before and after treatment (Paired 't' test).

Table 6: Comparison of Nasal Symptom Score for each treatment before and after treatment.

\begin{tabular}{|c|c|c|c|c|c|}
\hline \multirow{2}{*}{ Groups(n=13) } & \multicolumn{5}{|c|}{ Nasal symptom score } \\
\hline & Baseline score & End of treatment score & Mean change in score & $\mathbf{t}$ & $\mathbf{p}$ \\
\hline Cetirizine & $3.5 \pm 1.37$ & $1.65 \pm 1.4$ & $1.85 \pm-0.03$ & 6.6 & $0.0001 * * *$ \\
\hline Levocetrizine & $2.92 \pm 1.27$ & $1.15 \pm 1.5$ & $1.77 \pm-0.23$ & 7.056 & $0.0001 * * *$ \\
\hline Loratadine & $3.15 \pm 1.0$ & $1.35 \pm 0.87$ & $1.8 \pm 0.13$ & 7.046 & $0.0001 * * *$ \\
\hline Fexofenadine & $3.69 \pm 1.13$ & $1.5 \pm 1.1$ & $2.19 \pm 0.03$ & 5.447 & $0.0001 * * *$ \\
\hline $\mathrm{F}$ & 1.068 & 0.368 & & & \\
\hline $\mathrm{p}$ & 0.372 & 0.777 & & & \\
\hline
\end{tabular}

The values are expressed as mean $\pm \mathrm{SD}, \mathrm{n}=13$ patient. ***represents statistically significant of $\mathrm{p}<0.0001$ when compared before and after treatment (Paired 't' test).

Table 7: Comparison of Eye Symptoms Score for each treatment before and after treatment.

\begin{tabular}{|c|c|c|c|c|c|}
\hline \multirow{2}{*}{ Groups(n=13) } & \multicolumn{5}{|c|}{ Eye symptoms score } \\
\hline & Baseline score & End of treatment score & Mean change in score & $\mathbf{t}$ & $\mathbf{p}$ \\
\hline Cetirizine & $0.615 \pm 0.87$ & $0.461 \pm 0.97$ & $0.15 \pm-0.09$ & 0.519 & 0.613 \\
\hline Levocetrizine & $0.384 \pm 0.501$ & $0 \pm 0$ & $0.38 \pm 0.51$ & 2.739 & $0.018^{*}$ \\
\hline Loratadine & $0.380 \pm 0.506$ & $0.146 \pm 1.66$ & $0.234 \pm-1.15$ & 0.179 & 0.89 \\
\hline Fexofenadine & $0.769 \pm 0.44$ & $0.15 \pm 0.73$ & $0.62 \pm 0.06$ & 3.411 & $0.005^{*}$ \\
\hline $\mathrm{F}$ & 1.26 & 0.720 & & & \\
\hline $\mathrm{p}$ & 0.298 & 5.45 & & & \\
\hline
\end{tabular}

The values are expressed as mean $\pm \mathrm{SD}, \mathrm{n}=13$ patient. *represents statistically significant of $\mathrm{p}<0.05$ when compared before and after treatment (Paired ' $\mathrm{t}$ ' test).

Table 8: Comparison of activities Score before and after treatment.

\begin{tabular}{|llllll|}
\hline Groups(n=13) & Activities score & & & & \\
& Baseline score & End of treatment score & Mean change in score & t & p \\
\hline Cetirizine & $2.77 \pm 0.92$ & $1.55 \pm 0.46$ & $1.21 \pm 0.45$ & 7.95 & $<0.001 * *$ \\
\hline Levocetrizine & $2.34 \pm 0.96$ & $1 \pm 0.412$ & $1.54 \pm-0.66$ & 8.37 & $<0.001^{* *}$ \\
\hline Loratadine & $2.53 \pm 0.96$ & $1.26 \pm 0.50$ & $1.27 \pm 0.46$ & 7.75 & $<0.001^{* *}$ \\
\hline Fexofenadine & $2.54 \pm 0.96$ & $1.36 \pm 0.45$ & $1.17 \pm 0.51$ & 6.96 & $<0.001 * *$ \\
\hline F & 0.189 & 3.245 & & & \\
\hline p & 0.904 & 0.03 & & & \\
\hline
\end{tabular}

The values are expressed as mean $\pm \mathrm{SD}, \mathrm{n}=13$ patient. **represents statistically significant of $\mathrm{p}<0.001$ when compared before and after treatment (Paired ' $\mathrm{t}$ ' test), significant at $\mathrm{p}<0.05$ when compared between treatment groups using one-way ANOVA with post-hoc Bonferroni's test. 
Table 9: Comparison of Emotion Score for each treatment before and after treatment.

\begin{tabular}{|llllll|}
\hline Groups(n=13) & $\begin{array}{l}\text { Emotion score } \\
\text { Baseline score }\end{array}$ & End of treatment score & Mean change in score & t & p \\
\hline Cetirizine & $0.6923 \pm 0.63$ & $0.231 \pm 0.59$ & $0.46 \pm 0.03$ & 3.21 & $0.008^{*}$ \\
\hline Levocetrizine & $0.3077 \pm 0.48$ & $0 \pm 0$ & $0.30 \pm 0.48$ & 2.309 & $0.04^{*}$ \\
\hline Loratadine & $0.2308 \pm 0.43$ & $0.2308 \pm 0.83$ & $0 \pm-0.39$ & 0 & 1.0 \\
\hline Fexofenadine & $0.6923 \pm 0.48$ & $0.769 \pm 0.43$ & $0.62 \pm 0.20$ & 4.382 & $0.001^{* *}$ \\
\hline F & 3.0 & 0.614 & & & \\
\hline p & 0.04 & 0.609 & & & \\
\hline
\end{tabular}

The values are expressed as mean $\pm \mathrm{SD}, \mathrm{n}=13$ patient. *represents statistically significant of $\mathrm{p}<0.05$ when compared before and after treatment (Paired 't' test), ** represents statistically significant of $\mathrm{p}<0.001$.

ANOVA comparison between groups $(<0.05)$ i.e. Activities Score differs significantly for all the treatment groups. Subsequent pairwise contrasts using a Bonferroni adjustment reveals maximum reduction in Levocetirizine group. Activities Score differs significantly for all the treatment groups in the Table 8 .

When compared before and after treatment (Paired ' $t$ ' test) between treatment groups using one-way ANOVA it was observed that there is no variation in Emotion score in all the four treatment groups before or after treatment and there is no difference from treatment to treatment before or after the treatment in the Table 9.

\section{DISCUSSION}

The demographic characteristics of the study participants and the baseline symptom scores viz. Total Nasal Symptom Score (TNSS), Nasal Congestion Score prior to dosing are comparable among the four treatment groups (Table 1). All treatment groups showed significant improvements in the mean overall Rhino-conjunctivitis Quality of Life Questionnaire score, Overall RQLQ score is reduced to 49.72\% In Cetirizine group, in Loratadine group it is $62.72 \%$, in Fexofenadine group it is $62.65 \%$, whereas in Levocetirizine group it is $65.64 \%$ which is the maximum among the treatment groups (Table 2). The mean Sleep Score is decreased non-significantly in cetirizine, Loratadine, Fexofenadine treatment groups to $42.78 \%$ and $63.35 \%$, 50.64\% respectively, and maximally in Levocetirizine group i.e. $63.63 \%$ (Table 3). The mean Non Hay Fever Score (NHFS) is significantly decreased in all 4 treatment groups. NHFS is reduced to $82.85 \%, 100 \%, 74.67 \%$ and $99.74 \%$ respectively in Cetirizine, Levocetirizine, Loratadine and Fexofenadine treatment groups. Significant reductions were shown with Levocetirizine compared with Cetirizine and Loratadine (Table 4). The mean Practical Problem Score (PPS) is significantly decreased in all 4 treatment groups. PPS is reduced to $42.97 \%, 73.16 \%$, $55.56 \%$, and $57.92 \%$ respectively in Cetirizine, Levocetirizine, Loratadine and Fexofenadine treatment groups. Levocetirizine improved PPS in comparison with the other groups (Table 5). The mean Nasal Symptom Score (NSS) is reduced to $52.85 \%, 60.52 \%, 57.14 \%$, and
$59.35 \%$ respectively in Cetirizine, Levocetirizine, Loratadine and Fexofenadine treatment groups. The maximum reduction in NSS is seen in Levocetirizine group (Table 6). The mean Eye symptom Score is reduced to $24.39 \%, 98.95 \%, 61.57 \%$, and $80.62 \%$ respectively in Cetirizine, Levocetirizine, Loratadine and Fexofenadine treatment groups. The maximum reduction in Eye symptom Score is seen in Levocetirizine group (Table 7). The mean activities Score is to $43.68 \%, 65.81 \%, 50.19 \%$, and $46.06 \%$ respectively in Cetirizine, Levocetirizine, Loratadine and Fexofenadine treatment groups. The maximum reduction in activities Score is seen in Levocetirizine group (Table 8). The mean Emotion Score is reduced to $66.45 \%$ and $89.56 \%$ respectfully in Cetirizine and Fexofenadine treatment groups, whereas the maximum reduction is seen in Levocetirizine group i.e. 97.49\%, while there was no change with Loratadine (Table 9). The results of this study corroborate with those of a previous study done by Walter Canonica $G$ et al, study showed that long-term treatment with Levocetirizine improved HRQOL and health status in persistent allergic rhinitis (PER) patients assessed with RQLQ and SF-36. ${ }^{11}$ In Van Cauwenberge P et al, study Fexofenadine was better than Loratadine in improving QOL. Loratadine had no statistically significant effect on QOL compared with placebo. The incidence of adverse events was low and similar across the treatment groups. ${ }^{12}$ Segall $\mathrm{N}$ et al, assessed the efficacy and safety of levocetirizine in improving symptoms and health-related quality of life. Levocetirizine resulted in significantly greater improvement in TNSS and overall RQLQ score .Overall incidence of treatment-emergent adverse events was $14.4 \%$ for levocetirizine and $18.4 \%$ for placebo. The incidence of somnolence and fatigue was $0.7 \%$ and $1.8 \%$ with levocetirizine and $1.0 \%$ and $0 \%$ with placebo, respectively. ${ }^{13}$ The results of this study corroborate those of a previous Claus Bachert et al, study, The absenteeism and presenteeism, expressed in days per month per patient, were lower in the Levocetirizine group ( 0.18 vs 0.45 days in absenteeism and 0.70 vs 1.1 days in presenteeism). ${ }^{14}$ Anthi Rogkakou et al, concluded that Levocetirizine was welltolerated, safe, and suitable for continuous and long-lasting treatment. Furthermore, a long-term treatment with Levocetirizine reduces overall costs (direct and indirect costs) for both PER and associated comorbidities, with a consequently important impact on socioeconomic aspects. ${ }^{15}$ 
Lee CF et al, compared the efficacy of Cetirizine, Levocetirizine and placebo for the treatment of pediatric perennial allergic rhinitis. ${ }^{16}$ The effects of the three agents were compared with the Pediatric Rhino-conjunctivitis Quality of Life Questionnaire (PRQLQ). They revealed that both cetirizine and levocetirizine improved Total Symptom Score in comparison with the placebo group, and Cetirizine appeared to be more efficacious than Levocetirizine. The PRQLQ score showed significant reduction both in Cetirizine and Levocetirizine group, but there was no statistic significant difference between both groups

\section{CONCLUSION}

The present study is carried out in the patients of Allergic Rhinitis, visiting the ENT OPD at a tertiary care hospital. Health Related Quality of Life is assessed by using Rhinoconjunctivitis Quality of Life Questionnaire (RQLQ) followed by clinical examination to assess efficacy of the most commonly prescribed orally administered antihistamines that is Cetirizine, Levocetirizine, Loratadine and Fexofenadine. Levocetirizine has been better than other antihistamines when compared for the overall RQLQ score.

In Levocetirizine, RQLQ domain including items such as practical problems viz. Inconvenience to carry handkerchief, need to rub nose and need to blow nose repeatedly and nasal symptoms viz. Blocked nose, runny nose, sneezing and itchy nose showed a greater improvement as compared to other groups. The RQLQ domain including items such as the Non-Hay Fever symptoms viz. fatigue or tiredness also showed a greater improvement in the Levocetirizine group than other groups. Levocetirizine is a rapidly and sustainably effective antihistamine for the treatment of AR and not only does it provide statistically significant and clinically meaningful improvements in sleep and Emotional score viz. frustration, restlessness, irritation and embarrassment due to nasal discharge.

From the analysis of present comparative clinical study results of this study show that Levocetirizine control the symptoms of AR better as compared to Cetirizine, Loratadine and Fexofenadine. So Levocetirizine is a better choice in allergic rhinitis in comparison to others due to its cost effectiveness, tolerability and safety profile. These findings need to be confirmed by multicentric, randomized, double-blind studies involving a larger number of patients over a prolonged period. One of the strengths of the present study is that the administered HRQOL questionnaire, RQLQ, is a specifically developed instrument that takes into account the concerns of patients with AR. At the end of treatment period patients of all four study groups showed an improved perception of their HRQOL according to the RQLQ Significant improvements are reported in all dimensions: symptoms, daily activities, sleep, and psychological impact.

\section{ACKNOWLEDGEMENTS}

I am grateful to Dr. Ghaisas Virendra, Professor and Head of the department, Dr. Khan Mubarak, Dr. Parab Sapana, Dr. Mane Santosh the faculty at the department of ENT for allowing me to conduct study. I am thankful to Mrs. Raje Swati, Assistant Professor, department of Community Medicine who has provided valuable input for statistical analysis

\section{Funding: No funding sources}

Conflict of interest: None declared

Ethical approval: The study was approved by the Institutional Ethics Committee

\section{REFERENCES}

1. Bousquet $\mathrm{J}$, Bullinger $\mathrm{M}$, Fayol $\mathrm{C}$, Marquis $\mathrm{P}$, Valentin B, Burtin B. Assessment of quality of life in patients with perennial allergic rhinitis with the French version of the SF-36 Health Status Questionnaire. J Allergy Clin Immunol. 1994;94(2):182-8.

2. Bousquet J, Knani J, Dhivert H, Richard AL, Chicoye AN, Ware Jr JE, et al. Quality of life in asthma. I. Internal consistency and validity of the SF-36 questionnaire. Am J Respir Crit Care Med. 1994 Feb;149(2):371-5.

3. McHorney CA, Tarlov AR. Individual-patient monitoring in clinical practice: are available health status surveys adequate?. Qual Life Res. 1995 Aug 1;4(4):293-307.

4. McHorney CA. Generic health measurement: past accomplishments and a measurement paradigm for the 21st century. Ann Intern Med. 1997 Oct 15;127(8_Part_2):743-50.

5. Juniper EF, Guyatt GH, Griffith LE, Ferrie PJ. Interpretation of rhinoconjunctivitis quality of life questionnaire data. J Allergy Clin Immunol. 1996 Oct 1;98(4):843-5.

6. Juniper EF, Thompson AK, Ferrie PJ, Roberts JN. Validation of the standardized version of the Rhinoconjunctivitis Quality of Life Questionnaire. J Allergy Clin Immuno. 1999 Aug 1;104(2):364-9.

7. Juniper EF, Guyatt GH. Development and testing of a new measure of health status for clinical trials in rhinoconjunctivitis. Clin Exper Allergy. 1991 Jan;21(1):77-83.

8. Juniper EF, Howland WC, Robertsa NB, Thompson AK, King DR. Measuring quality of life in children with rhinoconjunctivitis. J Allergy Clin Immunol. 1998 Feb 1;101(2):163-70.

9. Juniper EF, Guyatt GH, Dolovich J. Assessment of quality of life in adolescents with allergic rhinoconjunctivitis: development and testing of a questionnaire for clinical trials. J Allergy Clin Immunol. 1994 Feb 1;93(2):413-23.

10. Demoly P, Bousquet PJ, Mesbah K, Bousquet J, Devillier P. Visual analogue scale in patients treated for allergic rhinitis: an observational prospective study 
in primary care: asthma and rhinitis. Clin Exp Aller. 2013 Aug;43(8):881-8.

11. Canonica GW, Bousquet J, Van Hammée G, Bachert C, Durham SR, Klimek L, et al. Levocetirizine improves health-related quality of life and health status in persistent allergic rhinitis. Resp Med. 2006 Oct 1;100(10):1706-15.

12. Van Cauwenberge P, Juniper EF. Comparison of the efficacy, safety and quality of life provided by fexofenadine hydrochloride $120 \mathrm{mg}$, loratadine $10 \mathrm{mg}$ and placebo administered once daily for the treatment of seasonal allergic rhinitis. ClinExp Allergy. 2000 Jun;30(6):891-9.

13. Segall N, Gawchik S, Georges G, Haeusler JM. Efficacy and safety of levocetirizine in improving symptoms and health-related quality of life in US adults with seasonal allergic rhinitis: a randomized, placebo-controlled study. Ann Allergy Asthma Immunol. 2010 Mar;104(3):259-67.

14. Bachert C, Bousquet J, Canonica GW, Durham SR, Klimek L, Mullol J, et al. Levocetirizine improves quality of life and reduces costs in long-term management of persistent allergic rhinitis. J Aller Clin Immunol. 2004;114(4):838-844.

15. Rogkakou A, Villa E, Garelli V, Canonica GW. Persistent Allergic Rhinitis and the XPERT Study. World Allergy Organ J. 2011;4(3 Suppl):S32-S36.

16. Lee CF, Sun HL, Lu KH, Ku MS, Lue KH. The comparison of cetirizine, levocetirizine and placebo for the treatment of childhood perennial allergic rhinitis. Pediatr Aller Immunol. 2009 Aug;20(5):493-9.

Cite this article as: Pentewar GS, Wagh RJ. Assessment of quality of life measured by Rhinoconjuctivits quality of life questionnaire in patients of allergic rhinitis treated with commonly used oral antihistaminics. Int J Basic Clin Pharmacol 2019;8:1830-7. 